\title{
REDUCTANT SUPPLY IN ISOLATED HETEROCYSTS OF ANABAENA SP. STRAIN CA
}

\author{
DHRUV KUMAR \\ Laboratory of Algal Biology, Centre of Advanced Study in Botany,
} Banaras Hindu University, Varanasi-221005, India

(Received April 15, 1991)

\begin{abstract}
Metabolically active heterocysts isolated from wild type Anabaena sp. strain CA under hydrogen incubation showed high endogenous acetylenereducing activity with or without nickel supplementation. The acetylene reducing activity of Ar-incubated heterocysts was significantly enhanced by fructose, erythrose, and reduced glutathione. The possible pathways related to reductant supply to heterocysts are discussed.
\end{abstract}

Under aerobic nitrogen-fixing conditions some filamentous cyanobacteria differentiate 5 to $10 \%$ of their vegetative cells into heterocysts. In isolated heterocysts, high rates of acetylene reduction (nitrogen fixation) occur in the presence of light and $\mathrm{H}_{2}(9,10,16,23)$. Nitrogen fixation requires both ATP and a low potential electron donor (12). Although it is clear that $\mathrm{H}_{2}$ provides electrons for acetylene reduction, the pathway of electron donation is still an open question $(4,6,7,13,14,18,20)$. Sturzl and Böger (24) have shown for whole cells of Anabaena variabilis that, under diazotrophic conditions, reducing equivalents resulting from carbohydrate breakdown are preferentially supplied to photosystem I. It has been reported that in isolated heterocysts, electrons for nitrogen fixation essentially come from the dark reactions of glycolysis (21). However, there is some controversy about the sources of reductant for nitrogen fixation by cyanobacteria in vivo. The high endogenous nitrogenase activity reported in isolated heterocysts of Anabaena sp. strain CA (9) throws some doubt on the function/operation of the conventional pathways of reductant supply and their sources $(21,24)$. Here we report the possibility of existence of a novel mechanism for the generation and supply of reductant to nitrogenase in isolated heterocysts of Anabaena sp. strain CA.

\section{MATERIALS AND METHODS}

The organism used for these studies was Anabaena sp. strain CA (ATCC

Address reprint requests to: Dr. Dhruv Kumar, Laboratory of Algal Biology, Centre of Advanced Study in Botany, Banaras Hindu University, Varanasi-221005, India. 
33047), a filamentous, heterocystous, marine cyanobacterium. Cultures were routinely grown in Borosil culture tubes containing $20 \mathrm{ml}$ of ASP-2 medium (26) with no combined nitrogen and $\mathrm{NaCl}$ content of $5 \mathrm{~g} / \mathrm{l}$. $100 \mathrm{nM}$ or $10 \mathrm{~mm}$ of filter-sterilized $\mathrm{NiCl}_{2} \cdot 6 \mathrm{H}_{2} \mathrm{O}$ or $\mathrm{NH}_{4} \mathrm{NO}_{3}$ respectively was added when required. The cultures were grown in $1 \% \mathrm{CO}_{2}$-in-air at $39 \pm 0.1^{\circ} \mathrm{C}$ and illuminated with six fluorescent lamps (F24/T12/D/HO) on either side of the bath $\left(300 \mu \mathrm{E} / \mathrm{m}^{2} / \mathrm{s}\right)$. Heterocyst isolation and other growth conditions were similar to those described earlier (10). For the isolation of heterocysts with high endogenous activity, cultures were grown to about $0.1 \mathrm{mg}$ dry wt $/ \mathrm{ml}$ in $1 \% \mathrm{CO}_{2}$-in-air and then switched to $1 \% \mathrm{CO}_{2}$-in- $99 \% \mathrm{Ar}$ for $12 \mathrm{~h}$. In labelling experiments, $75 \mu \mathrm{Ci}$ of $\mathrm{NaH}^{14} \mathrm{CO}_{3}$ (specific activity, $1 \mu \mathrm{Ci} / 10 \mu \mathrm{g}$ ) in $3 \mathrm{ml}$ was added into $17 \mathrm{ml}$ of culture suspension. For sparging 1\% $\mathrm{CO}_{2}$-in-air was used. Acetylene reduction and dry weights were determined as described previously (23).

Reagent or better grade biochemicals were purchased from Sigma Chemical Co., St. Louis, Missouri. Gold-labelled glucose and fructose were purchased from Aldrich Chem. Co., Milwaukee, Wisconsin.

\section{RESULTS AND DISCUSSION}

The kinetics of acetylene reduction by isolated heterocysts of Anabaena sp. strain CA under 90\% $\mathrm{H}_{2}+10 \% \mathrm{C}_{2} \mathrm{H}_{2}$ and $90 \% \mathrm{Ar}+10 \% \mathrm{C}_{2} \mathrm{H}_{2}$ have been reported earlier (23). Here we compare the kinetics of acetylene reduction with erythrose and fructose. The acetylene-reducing activity of heterocysts isolated from cultures grown in $1 \% \mathrm{CO}_{2}$-in-air was 2 and $1 \mu \mathrm{mol} \mathrm{C}_{2} \mathrm{H}_{4} / \mathrm{mg}$ dry wt/h under $90 \% \mathrm{H}_{2}+10 \%$ $\mathrm{C}_{2} \mathrm{H}_{2}$ and $90 \% \mathrm{Ar}+10 \% \mathrm{C}_{2} \mathrm{H}_{2}$, respectively. Nickel supplementation (100 nM $\mathrm{NiCl}_{2} \cdot 6 \mathrm{H}_{2} \mathrm{O}$ ) in the presence of hydrogen increased acetylene reduction by isolated heterocysts twofold, but had no effect on heterocysts under Ar (Fig. 1). Of the various carbon compounds surveyed for their ability to support acetylene reduction in isolated heterocysts under argon, only fructose and erythrose supported the activity. Fructose $(50 \mathrm{~mm})$ had no effect on acetylene reduction by the isolated heterocysts, but at a higher level $(350 \mathrm{~mm})$ it increased the endogenous activity from about $1 \mu \mathrm{mol}$ to almost $1.9 \mu \mathrm{mol} \mathrm{C}_{2} \mathrm{H}_{4} / \mathrm{mg}$ dry wt/h. This activity was almost equal to the activity reached under $90 \% \mathrm{H}_{2}$. Erythrose $(4 \mathrm{~mm})$ stimulated the acetylene-reducing activity of the heterocysts from $1 \mu \mathrm{mol}$ to $3.8 \mu \mathrm{mol} \mathrm{C}_{2} \mathrm{H}_{4} / \mathrm{mg}$ dry $w t / h$. Nickel supplementation had no effect on either fructose or erythrosesupported endogenous activity of isolated heterocysts (Fig. 1). Sorbose, mannitol, mannose, galactose, glucose, or glyceraldehyde-3-phosphate produced no significant effect on endogenous acetylene reduction by isolated heterocysts (data not shown).

The facts that the fructose concentration $(350 \mathrm{~mm})$ appears to be too high for any biochemical reaction and that fructose uptake is not a limiting factor (5) argues against the requirement for such a high concentration $(350 \mathrm{~mm})$ for enhancement of acetylene-reducing activity. At $250 \mathrm{~mm}$, fructose did not affect oxygen uptake, 


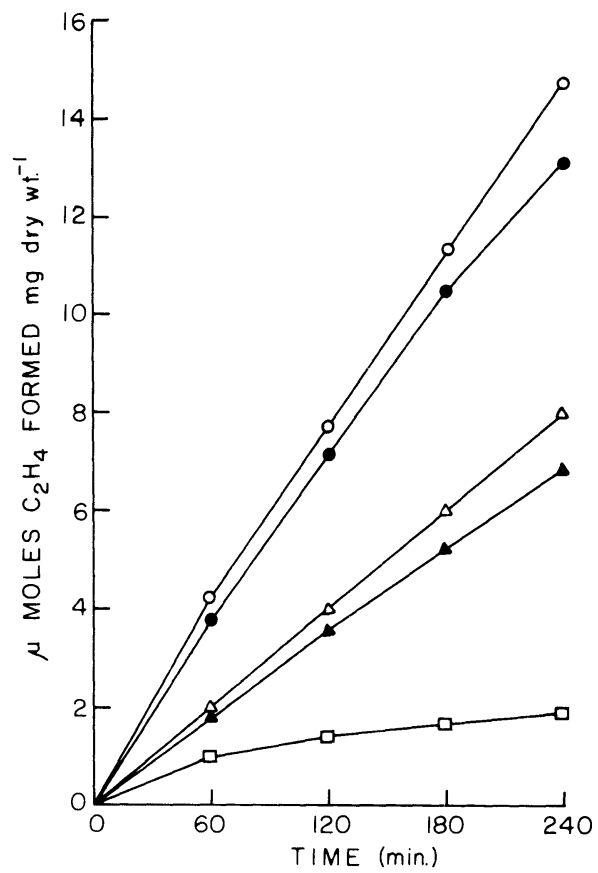

Fig. 1. Time course of acetylene reduction by isolated heterocysts from strain $\mathrm{CA}$ with or without added nickel in the growth medium and under an atmosphere of either $90 \% \mathrm{Ar}+10 \% \mathrm{C}_{2} \mathrm{H}_{2}$ or $90 \% \mathrm{H}_{2}+10 \% \mathrm{C}_{2} \mathrm{H}_{2}$. $\mathrm{NiCl}_{2} \cdot 6 \mathrm{H}_{2} \mathrm{O}$ was added to $100 \mathrm{nM}$ upon culture transfer, and the cells were allowed to grow for at least five generations in the presence of nickel in $1 \% \mathrm{CO}_{2}$ in air atmosphere. $90 \% \mathrm{H}_{2}+10 \% \mathrm{C}_{2} \mathrm{H}_{2}$ with nickel supplementation $(\bigcirc) ; 90 \% \mathrm{Ar}+10 \% \mathrm{C}_{2} \mathrm{H}_{2}$ with or without nickel $+4 \mathrm{mM}$ erythrose (๑); $90 \% \mathrm{H}_{2}+10 \% \mathrm{C}_{2} \mathrm{H}_{2}$ without nickel $(\triangle)$; $90 \% \mathrm{Ar}+10 \% \mathrm{C}_{2} \mathrm{H}_{2}$ with or without nickel $+350 \mathrm{~mm}$ fructose $(\Delta) ; 90 \% \mathrm{Ar}+10 \% \mathrm{C}_{2} \mathrm{H}_{2}(\square)$. Light intensity throughout the experiment was $300 \mu \mathrm{E} / \mathrm{m}^{2} / \mathrm{s}$.

but it decreased oxygen production by about 30\% in whole filaments. At present we are unable to explain the requirement of a higher concentration $(350 \mathrm{~mm})$ of fructose for enhancement of acetylene reduction by the isolated heterocysts. In contrast to the earlier observations $(14,18)$, the heterocysts isolated from Anabaena sp. strain CA do not show any inhibition of acetylene reduction under hydrogen by erythrose.

Erythrose- and fructose-supported endogenous acetylene-reducing activities, like $\mathrm{H}_{2}$-supported activity, were sensitive to 2,5-dibromo-3-methyl-6-isopropyl-pphenylenediamine (TMPD, $60 \mu \mathrm{M})(10)$. This suggests that electrons from the former pass through the cyt $b_{6} / f$-complex and PS I for ferredoxin reduction (21). The oxidative pentose phosphate pathway, which has erythrose-4-phosphate as an intermediate, is a major pathway in heterocysts for producing NADPH (11). Conversion of erythrose to triose before being metabolized via glycolytic enzymes, as believed to be present in heterocysts (1), appears unlikely in our case, since 
neither dihydroxyacetone phosphate nor 3-phosphoglyceraldehyde enhanced endogenous activity (data not shown). Utilization of fructose and erythrose, independent of oxygen (during the argon gas phase), points to the existence of some pathway other than the conventional oxidative pentose phosphate pathway for the supply of reductant and electrons to nitrogenase $(1,11,14,15,22)$. At present the possible presence of the bifidium pathway (17) in heterocysts of Anabaena sp. strain CA cannot be ruled out. However, the fate of acetate produced by this pathway remains to be explained.

Figure 2 shows the acetylene reduction rates of heterocysts isolated from cultures supplemented or not with nickel chloride and sparged with $1 \% \mathrm{CO}_{2}$-in99\% Ar for $12 \mathrm{~h}$. Hydrogen-supported nitrogenase activity was significantly enhanced from 2.0 to $4.2 \mu \mathrm{mol} \mathrm{C}_{2} \mathrm{H}_{4} \mathrm{mg}$ dry wt/h under argon sparging. Prein-

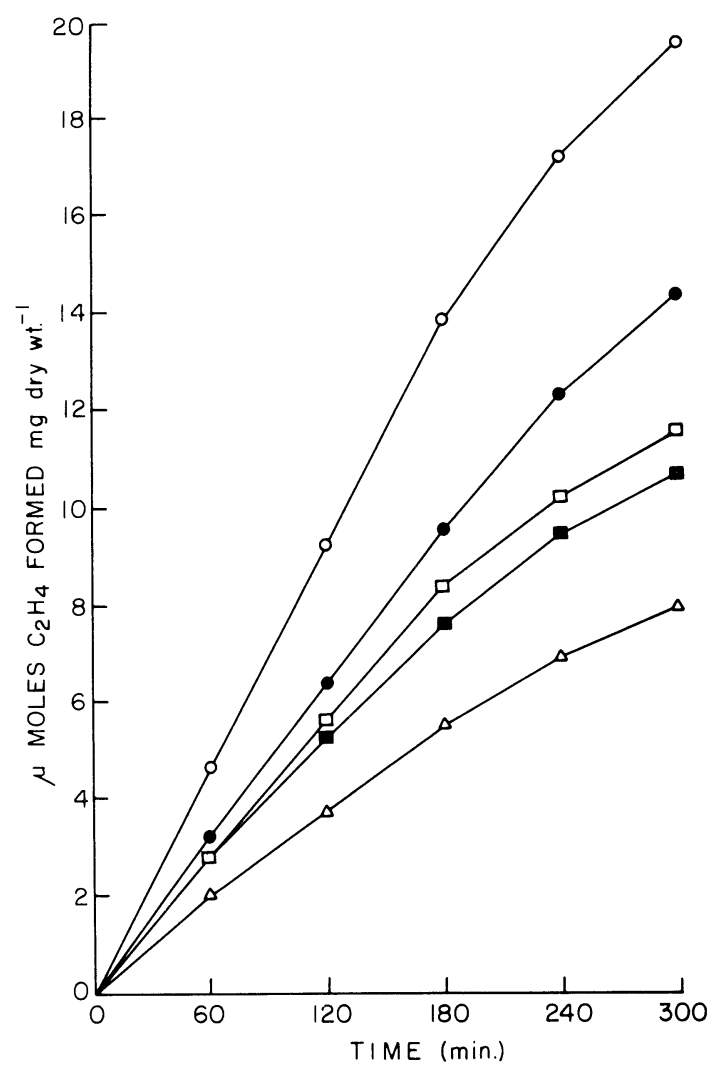

Fig. 2. Time course of acetylene reduction by isolated heterocysts of $1 \% \mathrm{CO}_{2}$ in 99\% Ar-sparged cultures. The cultures were sparged for $12 \mathrm{~h}$ and rates were measured under the following conditions: $90 \% \mathrm{H}_{2}+10 \% \mathrm{C}_{2} \mathrm{H}_{2}$ with or without nickel $(\bigcirc) ; 90 \%$ $\mathrm{Ar}+10 \% \mathrm{C}_{2} \mathrm{H}_{2}+0.3 \mathrm{~mm} \mathrm{GSH}(\bullet) ; 90 \% \mathrm{Ar}+10 \% \mathrm{C}_{2} \mathrm{H}_{2}$ with or without nickel $(\triangle)$; $1.5 \mathrm{~mm}(\square)$ and $0.15 \mathrm{~mm} \mathrm{GSH}$ under $90 \% \mathrm{Ar}+10 \% \mathrm{C}_{2} \mathrm{H}_{2}(\boldsymbol{\square})$. Cultures were grown for at least five generations with $100 \mathrm{nM}$ of $\mathrm{NiCl}_{2} \cdot 6 \mathrm{H}_{2} \mathrm{O}$. 
cubation under $1 \% \mathrm{CO}_{2}$-in-99\% $\mathrm{Ar}$ also increased the endogenous activity of isolated heterocysts from $1.0 \mu \mathrm{mol}$ to $2.0 \mu \mathrm{mol} \mathrm{C}_{2} \mathrm{H}_{4} \mathrm{mg}$ dry wt/h (Fig. 2). The increase in activity was not associated with the presence or absence of nickel. In fact nickel had no effect, even in a hydrogen atmosphere, on heterocysts isolated from cultures sparged in 1\% $\mathrm{CO}_{2}$-in-99\% Ar for $12 \mathrm{~h}$. Failure of nickel to increase acetylene reduction in the heterocysts isolated from culture sparged with $1 \%$ $\mathrm{CO}_{2}$-in-99\% Ar suggests that nickel supplementation may be conducive to the maximum obtainable activity from cultures grown under $1 \% \mathrm{CO}_{2}$-in-air.

The endogenous activity of isolated heterocysts was increased by the addition of different concentrations of reduced glutathione ( $\mathrm{GSH})$. The highest activity (3.8 $\mu \mathrm{mol} \mathrm{C}_{2} \mathrm{H}_{4} \mathrm{mg}$ dry wt/h) was obtained with $0.3 \mathrm{~mm}$ of GSH (Fig. 2). Glutathione reductase activity has been demonstrated in isolated heterocysts of Nostoc muscorum (8). A protein from Anabaena (25) with thioredoxin activity, when reduced by dithiothreitol, inactivated glucose-6-phosphate dehydrogenase (G6PDH). Surprisingly, inactivated G6PDH was not reactivated oxidatively by oxidized thioredoxin or $\mathrm{O}_{2}$, but could be reactivated by oxidized glutathione or $\mathrm{H}_{2} \mathrm{O}_{2}(25)$. These data indicate that if glucose-6-phosphate is active in supplying reductant in the heterocysts then there must be a mechanism to maintain it in an oxidized form. However, the heterocyst is generally viewed as an anaerobic to microaerobic system implying that oxidative activation may be restricted. The $\mathrm{H}_{2} \mathrm{O}_{2}$ activation of glucose-6-phosphate dehydrogenase may point to a photoreduction of $\mathrm{O}_{2}$ in heterocysts forming $\mathrm{H}_{2} \mathrm{O}_{2}$ as in photosystem I (25).

As a whole, the above results shed some light on the nature of the reductant supply in heterocysts. A continuous transport of small molecule(s) from vegetative cells to heterocysts appears unlikely. Heterocysts can be readily labelled by ${ }^{14} \mathrm{CO}_{2}$ (added as $\mathrm{NaH}^{14} \mathrm{CO}_{3}$ ) when incubated under $1 \% \mathrm{CO}_{2}$-in-99\% Ar for $12 \mathrm{~h}$. The incorporated radioactivity was not lost after repeated washings, which indicates the insoluble nature of the labelled product(s). Insignificant evolution of ${ }^{14} \mathrm{CO}_{2}(0.04$ $\mu \mathrm{mol} / \mathrm{mg}$ dry $\mathrm{wt}$ ) in $6 \mathrm{~h}$ and $6 \%$ loss of fixed/transferred radioactive material strongly precludes the functioning of the oxidative pentose phosphate pathway. Furthermore, the loss of only $20 \%$ of the dry weight of the heterocysts after $6 \mathrm{~h}$ (Table 1) under argon gas phase appears to support our view. To get 12 to $14 \mu \mathrm{mol}$ of $\mathrm{C}_{2} \mathrm{H}_{4} / \mathrm{mg}$ dry wt in $5 \mathrm{~h}$ under $90 \% \mathrm{Ar}+10 \% \mathrm{C}_{2} \mathrm{H}_{2}$ with reduced glutathione from endogenously active heterocysts (Fig. 2), we need to utilize about half of the amount of glucose or in other words half of the dry weight of heterocysts. But the carbohydrate deposition in heterocysts is only 43\% (3), the dry weight loss after $6 \mathrm{~h}$ incubation under $90 \% \mathrm{Ar}+10 \% \mathrm{C}_{2} \mathrm{H}_{2}$ is only $20 \%$, and microscopically heterocysts after $6 \mathrm{~h}$ incubation under argon look almost the same as at $0 \mathrm{~h}$.

In light, photosystem I can reduce ferredoxin and generate ATP for reduction of $\mathrm{N}_{2}$ to ammonia (2). There is now considerable evidence that $\mathrm{H}_{2}(6,7), \mathrm{NADH}$ (7), and NADPH (21) can feed electrons into the photosynthetic electron transport chain of heterocysts. We agree on this point, but continuous supply of electrons is needed for the functioning of photosystem I. To get all these electrons from 
Table 1. Accumulation of ${ }^{14} \mathrm{C}$-labelled radioactive compounds, evolution of $\mathrm{CO}_{2}$, loss of dry weight and acetylene reduction by heterocysts isolated from Anabaena sp. strain CA sparged with $1 \% \mathrm{CO}_{2}$ in $99 \% \mathrm{Ar}$ for $12 \mathrm{~h}$. All experiments, except isolation, were performed under $90 \% \mathrm{Ar}, 10 \% \mathrm{C}_{2} \mathrm{H}_{2}$. Isolation was performed under $100 \% \mathrm{Ar}$.

\begin{tabular}{|c|c|c|c|c|}
\hline Sample & $\begin{array}{l}\mathrm{dpm} / \mathrm{mg} \\
\text { dry wt }\end{array}$ & $\begin{array}{c}\mu \mathrm{mol} \mathrm{CO}_{2} \text { produced } \\
\mathrm{mg} \text { dry weight } \mathrm{h}^{-6}\end{array}$ & $\begin{array}{l}\mu \mathrm{mol} \mathrm{C}_{2} \mathrm{H}_{2} / \mathrm{mg} \\
\text { dry weight } \mathrm{h}^{-6}\end{array}$ & $\begin{array}{l}\mu \mathrm{g} \text { dry wt loss } / \mathrm{mg} \\
\text { dry weight } \mathrm{h}^{-6}\end{array}$ \\
\hline Heterocysts $(0 \mathrm{~h})$ & $\begin{array}{c}16,052,333 \\
(100 \%)\end{array}$ & - & - & - \\
\hline Heterocysts $(6 \mathrm{~h})$ & $\begin{array}{c}15,001,241 \\
(94 \%)\end{array}$ & 0.04 & 8.6 & $\begin{array}{c}203 \\
(20 \%)\end{array}$ \\
\hline
\end{tabular}

electron donors, the heterocysts must utilize their deposited/transferred carbon skeletons. In all carbon assimilation pathways, $\mathrm{CO}_{2}$ must be evolved and heterocysts must lose a significant proportion of dry weight as carbon. The oxyhydrogen reaction seems improbable in isolated heterocysts under argon gas phase unless they split $\mathrm{H}_{2} \mathrm{O}$.

From the above experimental data we conclude that heterocysts cannot work under argon gas phase without splitting $\mathrm{H}_{2} \mathrm{O}$ or utilizing some other novel mechanism for ATP and reductant supply to nitrogenase. However, it seems that no one has seen net $\mathrm{O}_{2}$ evolution in isolated heterocysts, which would imply the presence of a functional photosystem II. The oxyhydrogen reaction or possibly something like the violaxanthin cycle (19) can take good care of the oxygen produced by providing extra ATP for nitrogenase (oxyhydrogen reaction) or reversible binding and releasing of any oxygen formed in the light in a tightly controlled manner (violaxanthin cycle).

DK thanks the University Grants Commission, New Delhi, for appointing him as a UGC Research Scientist A.

\section{REFERENCES}

1) Bothe, H., Neuer, G., Kalbe, I., and Eisbrenner, G., Electron donors and hydrogenase in nitrogen-fixing microorganisms. In Nitrogen Fixation, ed. by Stewart, W. D. P. and Gallon, J. R., Academic Press, London (1980), p. 33-112.

2) Bottomley, P. J. and Stewart, W. D. P., ATP and nitrogenase activity in nitrogen-fixing heterocystous blue-green algae. New Phytol., 79, 625-638 (1977).

3) Cardemil, L. and Wolk, C. P., The polysaccharides from heterocyst and spore envelopes of a blue-green alga: Methylation analysis and structure of the backbones. J. Biol. Chem., 251, 29672975 (1976).

4) Eisbrenner, G., Roos, P., and Bothe, H., The number of hydrogenases in cyanobacteria. J. Gen. Microbiol., 125, 383-390 (1981).

5) Haury, J. F. and Spiller, H., Fructose uptake and influence on growth and nitrogen fixation by Anabaena variabilis. J. Bacteriol., 147, 227-235 (1981).

6) Houchins, J. P. and Burris, R. H., Light and dark reactions of the uptake hydrogenase in Anabaena 7120. Plant Physiol., 68, 712-716 (1981). 
7) Houchins, J. P. and Hind, G., Pyridine nucleotides and $\mathrm{N}_{2}$ as electron donors to the respiratory and photosynthetic electron transfer chains and to nitrogenase in Anabaena heterocysts. Biochim. Biophys. Acta, 682, 86-96 (1982).

8) Karni, L., Moss, S. J., and Tel-Or, E., Glutathione reductase activity in heterocysts and vegetative cells of the cyanobacterium, Nostoc muscorum. Arch. Microbiol., 140, 215-217 (1984).

9) Kumar, A., Tabita, F. R., and Van Baalen, C., High endogenous nitrogenase activity in isolated heterocysts of Anabaena sp. strain CA after nitrogen-starvation. J. Bacteriol., 155, 493-497 (1983).

10) Kumar, D. and Kumar, H. D., Protection of nitrogenase levels in dark-incubated cultures of Anabaena sp. strain CA by various carbon sources, and restoration of nitrogenase activity by oxygen. Br. Phycol. J., 25, 251-256 (1990).

11) Lockau, W., Peterson, R. B., Wolk, C. P., and Burris, R. H., Modes of reduction of nitrogenase in heterocysts isolated from Anabaena sp. Biochim. Biophys. Acta, 502, 298-308 (1978).

12) Mortenson, L. E. and Thorneley, R. N., Structure and function of nitrogenase. Annu. Rev. Biochem., 48, 387-418 (1979).

13) Neuer, G. and Bothe, H., The pyruvate: Ferredoxin oxidoreductase in heterocysts of the cyanobacterium Anabaena cylindrica. Biochim. Biophys. Acta, 716, 358-365 (1982).

14) Neuer, G. and Bothe, H., Electron donation to nitrogenase in isolated heterocysts of cyanobacteria. Arch. Microbiol., 143, 185-191 (1985).

15) Peterson, R. B. and Burris, R. H., Properties of heterocysts isolated with colloidal silica. Arch. Microbiol., 108, 35-40 (1976).

16) Peterson, R. B. and Burris, R. H., Hydrogen metabolism in isolated heterocysts of Anabaena 7120. Arch. Microbiol., 116, 125-132 (1978).

17) Poupard, J. A., Husain, I., and Norris, R. F., Biology of the Bifidobacteria. Bacteriol. Rev., 37, 136-165 (1973).

18) Privalle, L. S. and Burris, R. H., D-Erythrose supports nitrogenase activity in isolated Anabaena sp. strain 7120 heterocysts. J. Bacteriol., 157, 350-356 (1984).

19) Sapozhnikov, D. I., Investigation of the violaxanthin cycle. Pure Appl. Chem., 35, 47-61 (1973).

20) Scherer, S., Almon, H., and Böger, P., Interaction of photosynthesis, respiration and nitrogen fixation in cyanobacteria. Photosynth. Res., 15, 95-114 (1988).

21) Schrautemeir, B., Bohme, H., and Böger, P., In vitro studies on pathways and regulation of electron transport to nitrogenase with a cell-free extract from heterocysts of Anabaena variabilis. Arch. Microbiol., 137, 14-20 (1984).

22) Simpson, F. B. and Burris, R. H., A nitrogen pressure of 50 atms. does not prevent evolution of $\mathrm{H}_{2}$ by nitrogenase. Science, 224, 1095-1096 (1984).

23) Smith, R. L., Kumar, D., Xiakong, Z., Tabita, F. R., and Van Baalen, C., $\mathrm{H}_{2}, \mathrm{~N}_{2}$ and $\mathrm{O}_{2}$ metabolism by isolated heterocysts from Anabaena sp. strain CA. J. Bacteriol., 162, 565-570 (1985).

24) Sturzl, E. and Böger, P., Interaction of respiratory and photosynthetic electron transport in Anabaena variabilis Kutz. Arch. Microbiol., 132, 333--337 (1982).

25) Udvardy, J., Borbely, G., Juhusz, A., and Farkas, G. L., Fe ${ }^{3+}$ chelates mediate the oxidation modulation of cyanobacterial and chloroplast enzymes. FEBS Lett., 172, 11-16 (1984).

26) Van Baalen, C., Studies on marine blue-green algae. Bot. Mar., 4, 129-139 (1962). 